\section{ECCOMAS}

Proceedia
COMPDYN 2021

$8^{\text {th }}$ ECCOMAS Thematic Conference on Computational Methods in Structural Dynamics and Earthquake Engineering M. Papadrakakis, M. Fragiadakis (eds.)

\title{
A SIMPLIFIED APPROACH FOR THE VULNERABILITY ASSESSMENT OF REGULAR AND IRREGULAR REINFORCED CONCRETE BUILDINGS AT THE LARGE SCALE
}

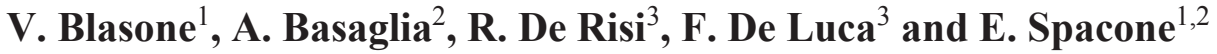 \\ ${ }^{1}$ Department of Civil Engineering and Architecture \\ University of Pavia \\ Via Adolfo Ferrata, 3, 27100 Pavia, Italy \\ e-mail: valentina.blasone01@universitadipavia.it \\ ${ }^{2}$ Department of Engineering and Geology \\ University "G. d'Annunzio" of Chieti-Pescara \\ Viale Pindaro 42, 65127 Pescara, Italy \\ e-mail: \{alberto.basaglia, enrico.spacone\}@unich.it \\ ${ }^{3}$ Department of Civil Engineering \\ University of Bristol \\ Queen's Building, University Walk, BS8 1TR, Bristol, UK \\ e-mail: \{flavia.deluca, raffaele.derisi\}@bristol.ac.uk
}

\begin{abstract}
Several European countries are likely to experience extensive damage following major earthquakes due to high vulnerability and exposure, associated with the age of the built environment and the presence of densely populated areas, respectively. For these reasons, largescale seismic risk assessment has a pivotal role. Given the large number of buildings to be assessed, indirect methods are usually the preferred option. However, simplified methodologies for reinforced concrete buildings have been recently developed, predominantly using non-linear time history analyses, and have shown to be a suitable alternative to indirect approaches. Simplified methodologies represent buildings as multi-degrees-of-freedom "sticklike" models, with the inter-storey behaviour modelled through an equivalent spring. These methodologies considerably reduce the computational effort yet achieving comparable accuracy with rigorous analyses. A major limitation of these methodologies is that they are applicable only to shear-type buildings, regular both in plan and in elevation. Aimed at overcoming this gap, the present work proposes a simplified method applicable to both regular and irregular reinforced concrete buildings. More specifically, each column is modelled separately with two uncoupled springs, one in each principal direction, to capture the torsional behaviour while retaining high computational efficiency. The proposed method is applied to a case study to demonstrate its capabilities.
\end{abstract}

Keywords: Vulnerability Assessment, Reinforced Concrete, Shear-Type, Irregular Buildings, Stick-Like Models, Non-Linear History Analyses 


\section{INTRODUCTION}

Cities are densely populated areas that may experience extensive damage and casualties in the occurrence of major earthquakes. Hence, large-scale seismic risk assessment is of paramount importance to assess expected damage and plan mitigation strategies. Given the high number of buildings to be assessed, indirect methods have been preferred to methods based on detailed structural analyses that use Finite Element (FE) modelling. More specifically, models based on vulnerability indices [1], or on the classification of buildings into typological classes (e.g. [2] and [3]) have been developed. More recently, Polese et al. [4] proposed an innovative method based on buildings inventory (combining Census-based data and interview-based CARTIS approach) and seismic damage assessment. Indirect methods have demonstrated to provide acceptable results in a general framework. However, their reliability is strictly dependent upon the amount and quality of data and they are drastically simplified with respect to a detailed modelling approach. Direct methods include the capacity spectrum method [5], which adopts Single-Degree-Of-Freedom (SDOF) building models and pushover (PO) analysis to predict damage. Lu, Xinzheng et al. [6] showed that the method provides a good estimation of global building behaviour (in terms of strength and ductility), with moderate computational effort but it has important limitations, e.g., it cannot represent concentration of damage at the different storeys.

Recently, as the computational power increases and becomes more easily available, direct Non-Linear History Analysis (NLHA)-based methodologies have become increasingly popular (e.g., [7], [8] and [9]). In this way, it is possible to fully describe the characteristics of the soil on which buildings are based (in time and frequency domain) through suitable ground motion selection, or more sophisticated approaches, along with the non-linear characteristics of the buildings [6]. These methodologies require a direct simplified model for buildings, to compute the Engineering Demand Parameters (EDP) (e.g., inter-storey drift, peak floor acceleration) needed to predict damage. Typically, buildings are directly implemented, usually as Multiple-Degree-Of-Freedom (MDOF) shear systems. More specifically, each storey is represented by a concentrated mass and a non-linear spring, thus considerably reducing the computational effort compared to refined models, yet increasing the accuracy compared to the indirect procedures. Backbone curves of springs are calibrated based on simulated design procedure [7] or adopting a multi-objective Genetic Algorithm (GA) procedure that employs the results of non-linear cyclic pushover analyses done on refined non-linear models (e.g., [9]).

A drawback of the simplified models developed to date is that they are applicable only to shear-type buildings, regular both in plan and in elevation. This drawback is relevant for two main reasons:

- structural irregularities, due to non-symmetric distribution of load resisting elements (stiffness and strength eccentricity) and non-symmetric distribution of masses are particularly common in old buildings;

- torsion can adversely affect the seismic performance of buildings with any type of eccentricity [10], [11] and [12].

For these reasons, a simplified model capable of capturing the torsional behaviour of buildings is needed for NLHA-based methodologies. In this work, a model is proposed which aims to represent the flexural and torsional behaviour of Reinforced Concrete (RC) frame structures in a simplified and light-computational manner. The applicability of the model is general since it is suitable for different structure configurations, not necessary shear-type. It can reproduce the behaviour not only of regular buildings, but also of irregular buildings with torsional behaviour, that have not been considered before. The main software used is OpenSees 
along with STKO [13], a Graphical User Interface (GUI) with a pre and post processor for OpenSees.

\section{METHODOLOGY}

In the proposed simplified model, the building is represented by a three-dimensional (3D) MDOF model, fully described by the columns. The non-shear-type behaviour of the building is achieved by adopting calibrated shear-inter storey drift (V-ID) curves for each column. At the local level, each column is represented by two uncoupled translational springs in the two main horizontal directions. If the centre of mass and the centre of stiffness of the building do not coincide, coupling is automatically achieved at the global level, see Figure 1, thus capturing the torsional behaviour.

Each column is modelled in OpenSees as a zeroLength element with two nodes. A rigid material is assigned to all the Degrees Of Freedom (DOFs), except for the translations along the local axis (2) and (3) (assuming the local axis (1) always directed along the axis of the column) and for the rotation against the local axis (1) (torsion), which is kept released. Calibrated backbone curves are assigned to the two translational DOFs (see Figure 1).

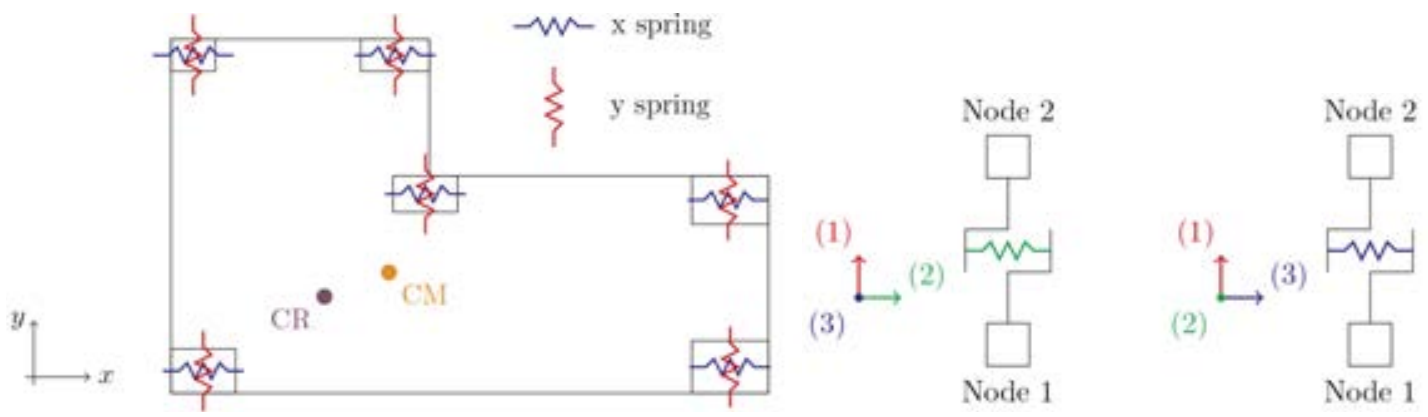

Figure 1. (left) Scheme of the general idea for the storey model (CR: Centre of Stiffness, CM: Centre of Mass); (right) model of the springs, in local axes (2) and (3).

Each spring is defined by an appropriate V-ID backbone curve, that represents the column behaviour in the considered direction. First, an analytical parameter-dependent V-ID curve is defined. A trilinear curve is adopted, and no refined models are needed for this first step. In a second phase, the parameters are calibrated to represent the behaviour of the column in its configuration (e.g., boundary conditions), accounting implicitly for beams flexibility. To derive the analytical parameter-dependent V-ID curve, the method stems from the definition of a trilinear sectional moment-chord rotation $(\mathrm{M}-\theta)$ curve, which can be simply defined independently from column boundary conditions. The model proposed by Ibarra [14] is used in this work. Using basic structural mechanics relationships and assuming a shear-type configuration for the column, the $\mathrm{M}-\theta$ curve is used to find the corresponding analytical shear-type V-ID curve, which maintains the same shape of the M- $\theta$ curve, see Figure 2.
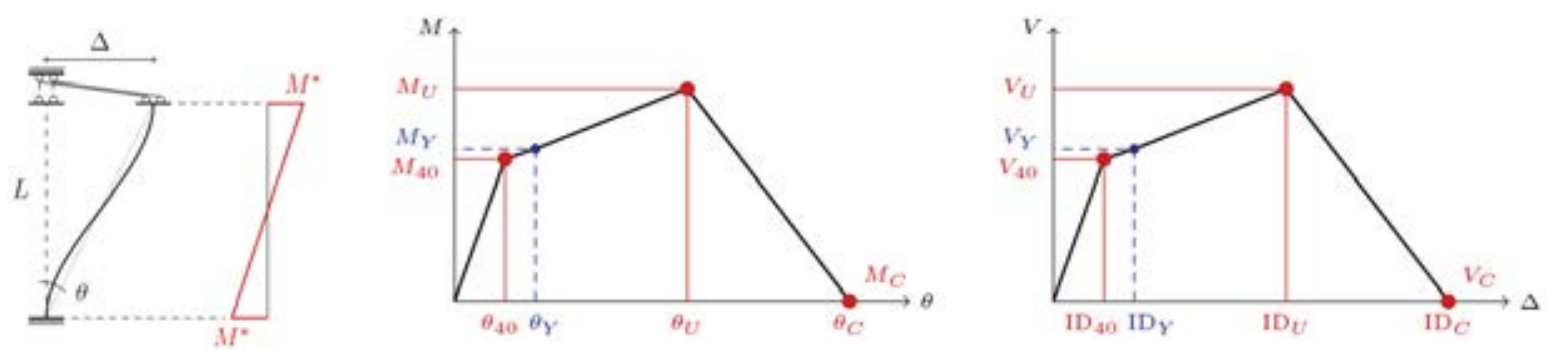

Figure 2. (left) column model with two end rotational springs; (centre) moment-rotation (M- $\theta$ ) curve by [14]; (right) V-ID curve for the column under the shear-type assumption. 
The expressions for the points defining the shear-type V-ID relationship are then modified through a set of five parameters and are presented in Eq. 1 (for details on moment/rotation calculation see [14] and [15]).

$$
\begin{gathered}
V_{40}=2 M_{40} / L \cdot \mu \\
V_{Y}=2 M_{Y} / L \cdot \mu \\
V_{U}=2 M_{U} / L \cdot \kappa \\
V_{C}=0
\end{gathered}
$$

$$
\begin{gathered}
I D_{40}=\theta_{40} \cdot L / \alpha \\
I D_{Y}=\theta_{40} \cdot L / \alpha+\left(\theta_{Y}-\theta_{40}\right) \cdot L / \beta \\
I D_{U}=\theta_{40} \cdot L / \alpha+\left(\theta_{U}-\theta_{40}\right) \cdot L / \beta \\
I D_{C}=\theta_{C} \cdot L / \gamma
\end{gathered}
$$

Changes in the values of the parameters (i.e., $\alpha, \beta, \gamma, \mu, \kappa)$ modify, in turn, the shape of the $\mathrm{V}$-ID curve. The value of each parameter can be adjusted to represent the realistic behaviour of the column. Indeed, the analytical curves were purposely defined such that the values of the parameters could be directly retrieved making use of some data-driven techniques (e.g., machine learning) that, once developed, would make the definition of the final curve a rapid process. However, the development of this algorithm is beyond the scope of this paper and will be addressed in future works.

Refined reference curves are used in this work. In this perspective, parameters are found by comparison between the analytical and the numerical curves, either by trial-and-error process (i.e., manually changing the values until the approximation is acceptable) or making use of more automatised and accurate procedures. The latter approach is adopted herein, more specifically the parameters values are evaluated using a GA procedure, with the objective of finding the parameters for which the error between the numerical and analytical curves, see Eq. 2, is minimized. More insights about the proposed methodology can be found in [16].

$$
\sqrt{\sum_{i}\left(V_{\text {numerical }, i}-V_{\text {analytical }, i}\right)^{2}}
$$

\section{CASE STUDY}

The building considered as case study is adapted from a structure dating back to the $1970 \mathrm{~s}$ [17], whose characteristics have been slightly modified for the purpose of the current work. The building has three storeys, the first storey is $3.4 \mathrm{~m}$ high, the second and third storeys are $3.05 \mathrm{~m}$ high. The length of all spans is $3.75 \mathrm{~m}$. Column sections may be divided into three groups, indicated in the following as $\mathrm{CA}, \mathrm{CB}$, and $\mathrm{CC}$, see Figure 3. Within each group, columns have also different sections for each floor. Moreover, columns at the first, second and third storey are subject to an axial load of $0.1 \mathrm{P}_{\mathrm{cu}}, 0.2 \mathrm{P}_{\mathrm{cu}}$ and $0.3 \mathrm{P}_{\mathrm{cu}}$, respectively, where $\mathrm{P}_{\mathrm{cu}}$ is the ultimate axial compressive bearing capacity of the column. Beams are all deep with section $30 \mathrm{~cm} \times 50 \mathrm{~cm}$. The concrete and steel reinforcement properties are $\mathrm{f}_{\mathrm{c}}=23.5 \mathrm{MPa}, \mathrm{f}_{\mathrm{y}}=$ $440 \mathrm{MPa}$. They are taken from [17] and represent mean values.

A detailed model is considered as benchmark for the simplified model. Both the columns and the beams are modelled as lumped plasticity elements. The model is fixed at the base and a rigid diaphragm is implemented at each storey level. The axial loads are applied as concentrated forces and the masses are added as nodal masses, equal in the three translational DOFs. A Rayleigh damping of 5\% is applied, taking as reference the first and second frequencies of vibration of the structure, as derived from the modal analysis.

The simplified model is built as described in Section 2. Figure 4 shows the calibration of the V-ID curves for the frame $2 \mathrm{Y}$ of Figure 3. A set of all five coefficients equal to 1 would mean that the shear-type model perfectly captures the behaviour of the specific column. 


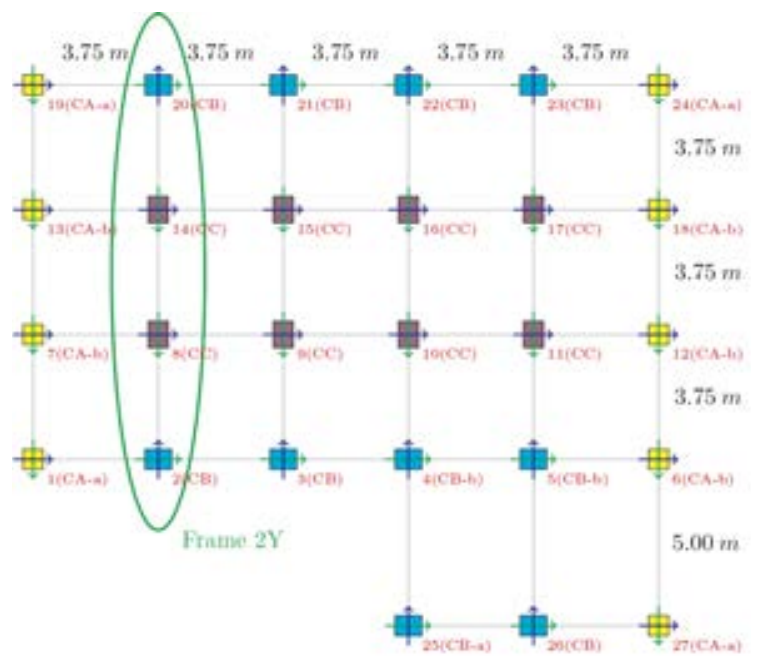

Figure 3. Plan view of the case study building; identification of frame $2 \mathrm{Y}$.
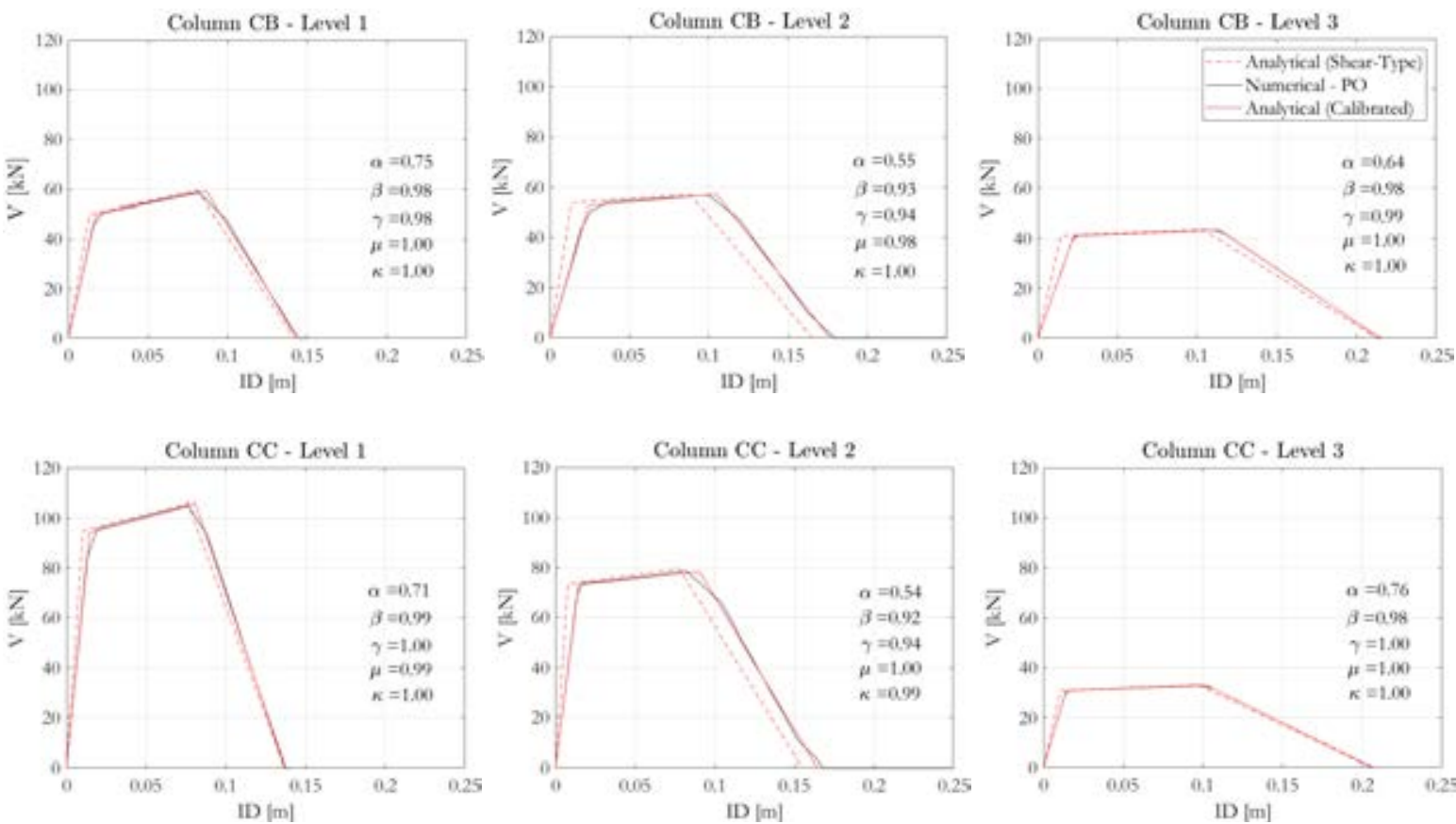

Figure 4. Comparison of analytical (shear-type), numerical and analytical (calibrated) V-ID curves for frame $2 \mathrm{Y}$.

\subsection{Pushover analysis}

A pushover analysis is performed on both detailed and simplified models along both $\mathrm{x}$ and $y$ axes of the model (see Figure 1). The pushover load is applied by following a uniform distribution along the height, hence the same load is applied at each storey, at its centre of mass (CM). The load is applied with 2,000 increments through the DisplacementControl static integrator in OpenSees, setting the top CM as control node and a target displacement of $0.2 \mathrm{~m}$ (corresponding to an average roof drift ratio of $\sim 2 \%$ ). The analysis is repeated in both global horizontal directions, $\mathrm{x}$ and $\mathrm{y}$, and results are investigated in the direction of loading.

Results are compared by plotting the total base shear-top displacement curve and the Interstorey Drift Ratio (IDR) values along the height. Figure 5 and Figure 6 show results for the analysis in the $\mathrm{x}$ and $\mathrm{y}$ directions, respectively. Results show good correspondence between the two models, with the larger differences found in the analysis performed in the global $y$ 
direction. Yet, the simplified model underestimates the maximum base shear by only $2.3 \%$. A final comparison is shown in Figure 7, where the deformed shape of the structure at a fixed time instant (step 1,000) is plotted. Both figures refer to the pushover in y, where the torsional behaviour is more evident, and show that the torsional behaviour of the building is perfectly captured by the simplified model.
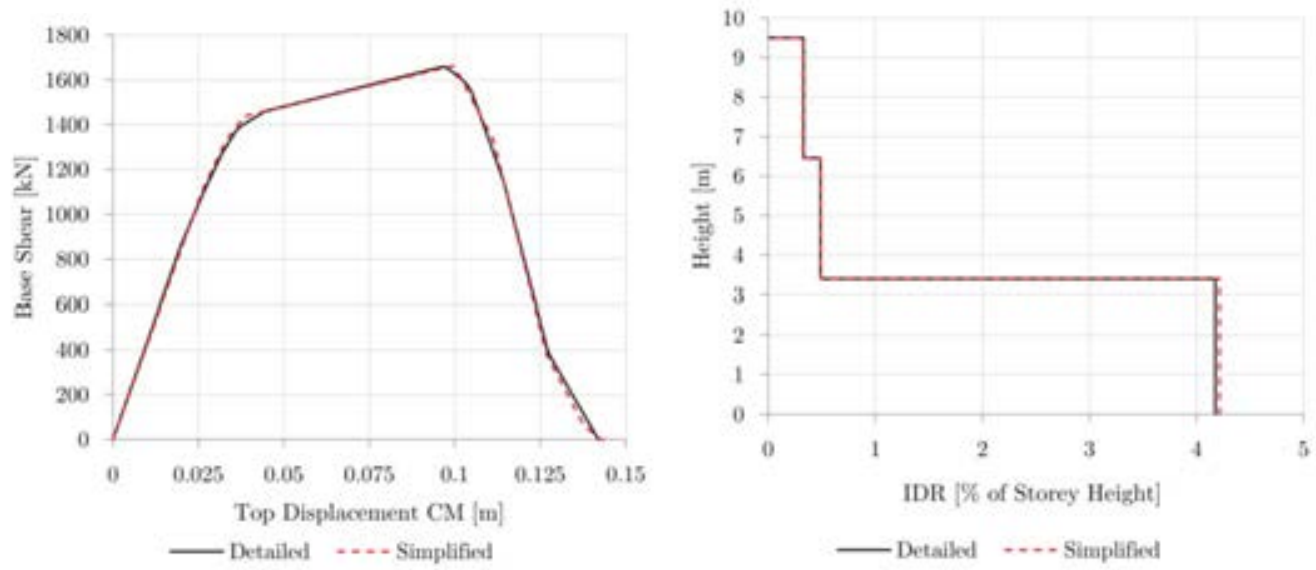

Figure 5. Results from the pushover in $\mathrm{x}$, base shear-top displacement and height-IDR plots.
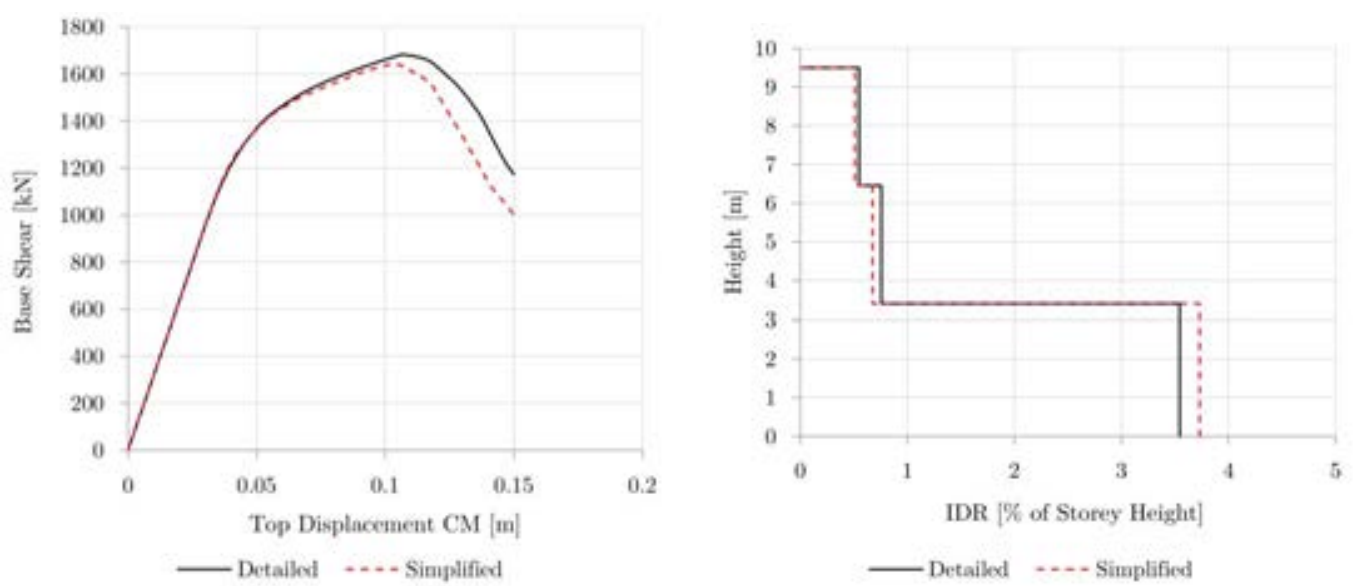

Figure 6. Results from the pushover in y, base shear-top displacement and height-IDR plots.

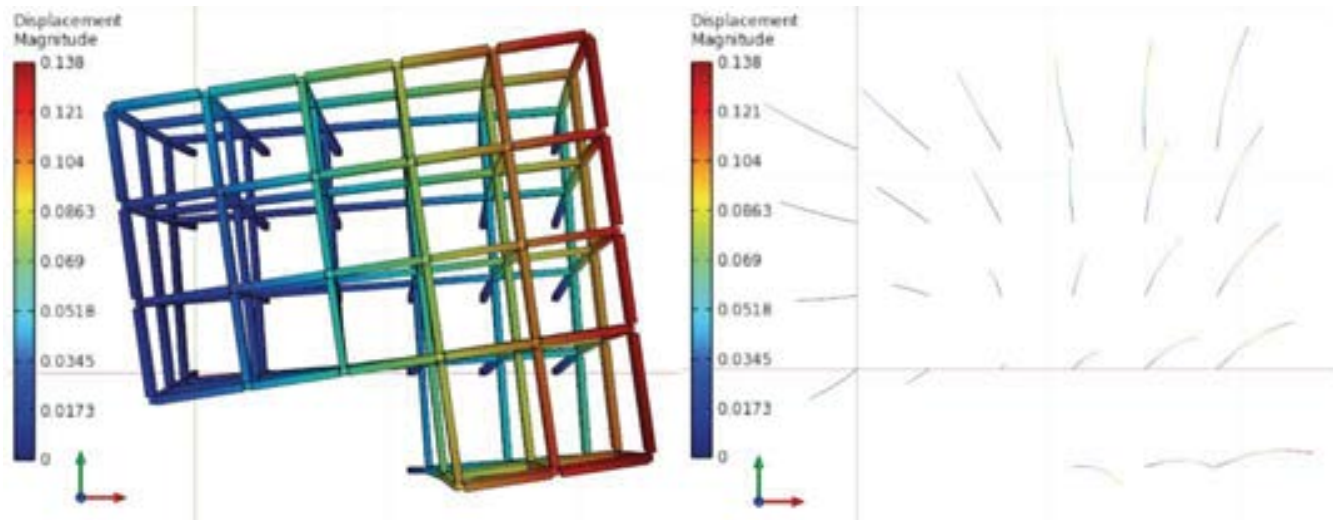

Figure 7. Results from the pushover in y, deformed shape at step 1000 for the (left) benchmark detailed model and (right) simplified model; colours represent the displacement in y (units: m). 


\subsection{Non-Linear History Analysis}

A non-linear history analysis is performed on both the detailed and simplified models. The signal is a natural accelerogram selected from the PEER NGA database, related to the Imperial Valley earthquake of 1979 , see Figure 8 . The PGA is $0.24 \mathrm{~g}$, and the total duration of the signal is $50 \mathrm{~s}$.

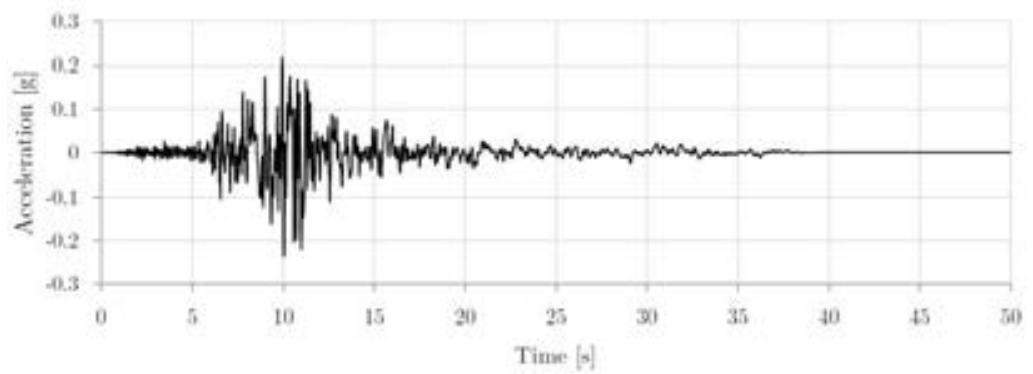

Figure 8. Imperial Valley accelerogram used to perform NLHA.

The acceleration history is defined in STKO as a path time series and is applied through the UniformExcitation command. The analysis is performed using the Newmark transient integrator with parameters $\beta=0.25$ and $\gamma=0.5$. The time step is $0.01 \mathrm{~s}$ and is taken also as time step for the analyses, deriving consequently the initial total number of steps. The adaptive time step is used in the detailed model to achieve convergence. The analysis is first performed separately in the global $\mathrm{x}$ and $\mathrm{y}$ directions. Then, a last analysis in which the seismic load is applied to both the global directions, $x$ and $y$, is performed. Due to the non regularity of the building, the results are investigated in both directions. For brevity, only the analysis with the load applied in both directions and the results in the y direction are shown herein. Results from other analyses indicate very similar behaviour, for more details, see [16].

Results in terms of maximum base shear as absolute value show differences lower than $0.5 \%$, see Table 1 and Figure 9. The negligible difference is further confirmed by the total base shear-top CM displacement plots, see Figure 10. In terms of EDP, the IDR is the parameter that is best represented by the simplified model, with very small differences. The Peak Floor Acceleration (PFA) results show a very good correspondence between the two models too, see Figure 11.

The simplified model presents significant advantages in terms of computational efficiency reaching convergence much faster, with an overall shorter analysis duration. The gain in computational efficiency is more evident when NLHA are performed. More specifically, in the non-linear dynamic case, the simplified model shows a reduced analyses duration to approximately $1 / 4$ of the computational time necessary to bring the detailed model to convergence in a case where no convergence issues arise, and up to approximately $1 / 100$ when convergence problems in the detailed model arise, thus the time step needs to be reduced. The latter case is the one experienced in most of the analyses performed.

Table 1. NLHA - Imperial Valley signal, analysis in $\mathrm{x}+\mathrm{y}$, results in terms of maximum base shear.

\begin{tabular}{ccccc}
\hline & & Simplified & Benchmark & Relative Difference \\
\hline Max Base & $\mathrm{x}$ & 1513.0 & 1516.5 & $0.2 \%$ \\
\cline { 2 - 5 } Shear [kN] & $\mathrm{y}$ & 1791.7 & 1786.0 & $0.3 \%$ \\
\hline
\end{tabular}




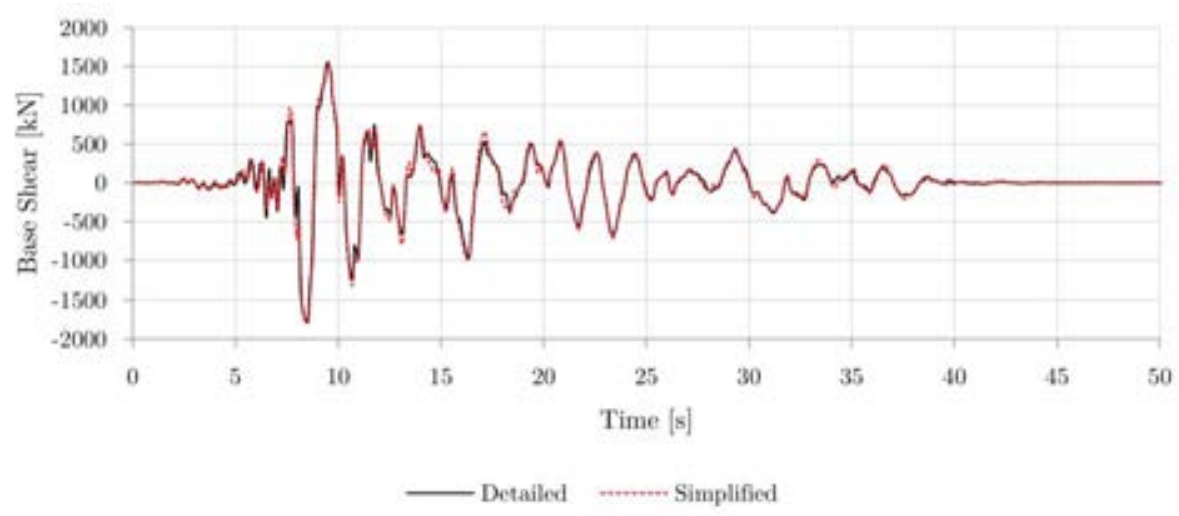

Figure 9. NLHA - Imperial Valley signal, analysis in $\mathrm{x}+\mathrm{y}$, results in $\mathrm{y}$, total base shear history.
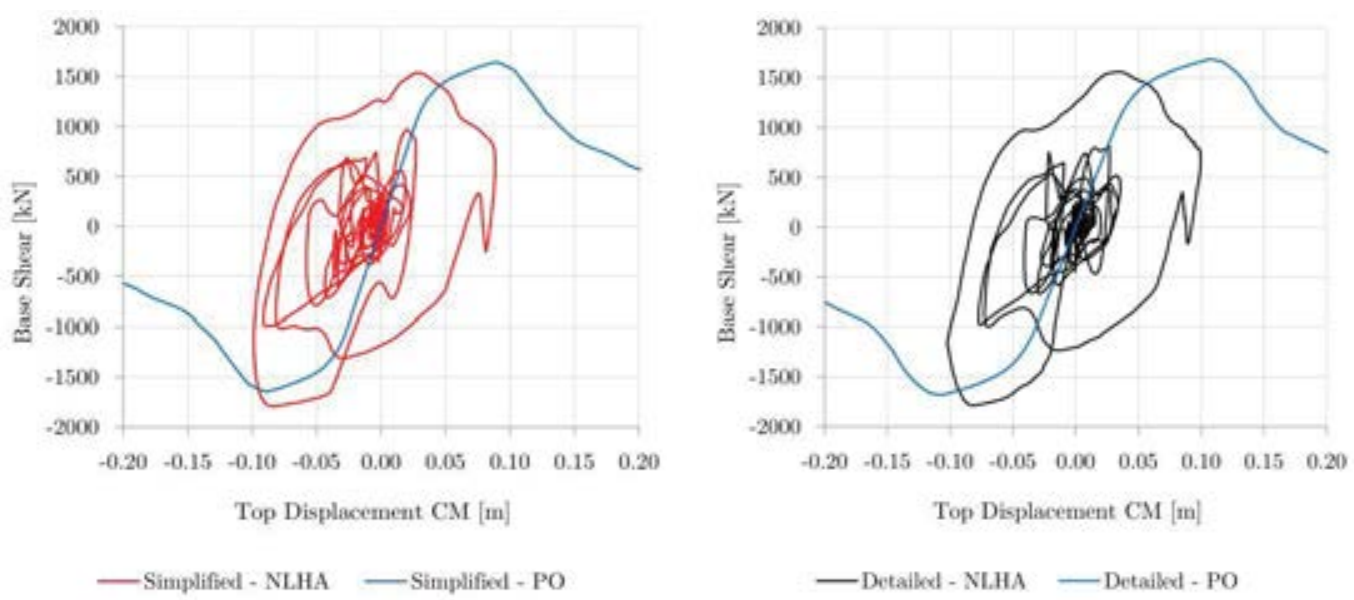

Figure 10. NLHA - Imperial Valley signal, analysis in $\mathrm{x}+\mathrm{y}$, results in $\mathrm{y}$, total base shear versus top displacement.
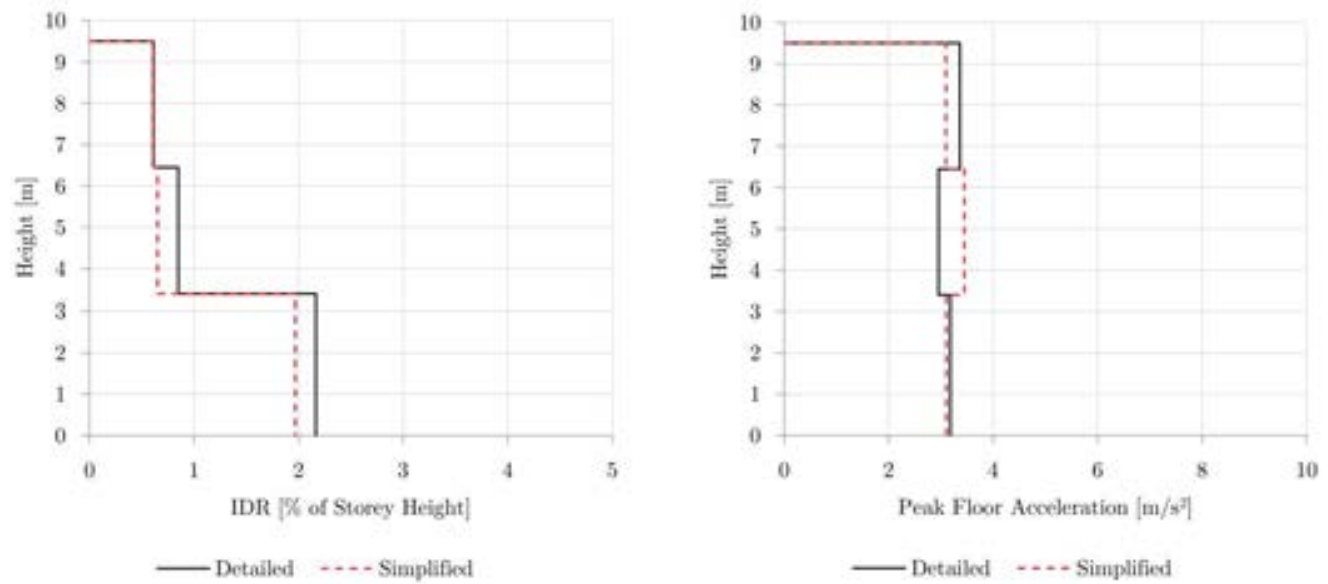

Figure 11. NLHA - Imperial Valley signal, analysis in $\mathrm{x}+\mathrm{y}$, results in $\mathrm{y}$, IDR and PFA distribution.

\section{SUMMARY AND CONCLUSIONS}

In this paper, a simplified model for reinforced concrete buildings that is suitable for large scale non-linear history analysis-based seismic assessment was proposed. The novelty of the proposed model is the applicability also to non-shear-type configurations and the ability to capture the torsional behaviour of irregular buildings. Both aspects are very common when 
dealing with an existing building stock. The proposed model is a three-dimensional multiple degree of freedom column-based model, in which each column is represented by two uncoupled translational springs. In this way, coupling at the global level can be automatically obtained, making the model able to represent torsion. The non-shear-type behaviour is instead achieved by specific calibration of the shear-inter-storey drift relationships for the column backbone curves. Refined analyses on two-dimensional sub-frames together with a genetic algorithm are used in this work, however the analytical expressions developed to describe the shear-inter-storey drift curves are suitable for employment in a more efficient data-driven procedure that will be addressed in future research.

The benchmark analyses showed a very good correspondence between the refined and simplified results, both in terms of non-linear static and non-linear dynamic analyses. As for non-linear history analyses, the simplified model is perfectly suitable to represent the base shear history with negligible difference in terms of maximum base shear results. The investigated engineering demand parameters (i.e., inter-storey drift ratio and peak floor acceleration) are correctly captured by the simplified model, too. The model is accurately able to represent the torsional behaviour of the building. In terms of efficiency, the proposed model led to faster convergence and considerable decrease in computational times, making it a competitive option for large-scale assessment applications.

\section{REFERENCES}

[1] GNDT-SSN, Scheda di esposizione e vulnerabilità e di rilevamento danni di primo. 1994.

[2] G. Grünthal, European macroseismic scale 1998. Tech. rep. European Seismological. 1998.

[3] S. a. S. G. Lagomarsino, Macroseismic and mechanical models for the vulnerability and damage assessment of current buildings. Bulletin of Earthquake Engineering, vol. 4.4, pp. 415-443, 2006.

[4] M. Polese, M. Di Ludovico, M. Gaetani d'Aragona, A. Prota and G. Manfredi, Regional vulnerability and risk assessment accounting for local building typologies. International Journal of Disaster Risk Reduction, 2019.

[5] FEMA, Multi-hazard Loss Estimation Methodology-Earthquake Model. 2012.

[6] X. e. a. Lu, A coarse-grained parallel approach for seismic damage simulations of urban areas based on refined models and GPU/CPU cooperative computing. Advances in Engineering Software, vol. 70, pp. 90-103, 2014.

[7] C. X. a. X. Lu, X. Lin and Z. X. a. L. Ye, Parameter Determination and Damage Assessment for THA-Based Regional Seismic Damage. Journal of Earthquake Engineering, 21:3, pp. 461-485, 2017.

[8] C. Xiong, X. Lu, H. Guan and Z. Xu, A nonlinear computational model for regional seismic simulation of tall buildings. Bulletin of Earthquake Engineering, p. 1047-1069, 2016.

[9] M. G. d'Aragona, M. Polese and A. Prota, Stick-IT: A simplified model for rapid estimation of IDR and PFA for existing low-rise symmetric infilled RC building typologies. Engineering Structures, vol. 223, pp. 111-182, 2020.

[10] S. Anagnostopoulos, M. Kyrkos and K. Stathopoulos, Earthquake induced torsion in buildings: critical review and state of the art. Earthquakes and Structures, pp. 305-377, 2015.

[11] Rajeev, Pathmanathan and Tesfamariam, Seismic fragilities for reinforced concrete 
buildings with consideration of irregularities. Structural Safety, pp. 1-13, 2012.

[12] Trifunac and Mihailo, Effects of torsional and rocking excitations on the response of structures. in Earthquake Source Asymmetry, Structural Media and Rotation Effects, Springer, 2006, pp. 569-582.

[13] Petracca, M., Candeloro, F. \& Camata, G. (2017). STKO user manual. ASDEA Software Technology, Pescara.

[14] Ibarra, Medina and Krawinkler, Hysteretic models that incorporate strength and stiffness deterioration. Earthquake Eng. Struct. Dyn., 2005 a.

[15] Ibarra and Krawinkler, Global Collapse of Frame Structures Under Seismic Excitations. Department of Civil and Environmental Engineering Stanford University, 2005 b.

[16] V. Blasone, Building and soil modelling for non-linear history analyses at the urban scale: development of a simplified model for reinforced concrete buildings and application to a case study in Benevento. MS thesis, University of Pavia and IUSS Pavia, 2020.

[17] I. \&. D. M. Iervolino, Foreword to the Special Issue for the RINTC (The Implicit Seismic Risk of Code-Conforming Structures) Project. Journal of Earthquake Engineering, 2018. 